\title{
É Possível Desenvolver a Autorreflexão no Estudante de Primeiro Ano que atua na Comunidade? Um Estudo Preliminar
}

\section{Is it Possible for First Year Students Working in the Communityto Develop Self-Reflection? A PreliminaryStudy}

Alice Yamashita Prearo Fernanda Miranda Fumelli Monti Elena Barragan ${ }^{\text {II }}$

\section{PALAVRAS-CHAVE: \\ - Educação Médica. \\ - Educação em Enfermagem. \\ - Atenção Primária à Saúde. \\ - Avaliação Educacional.}

\section{KEYWORDS:}

- Education, Medical.

- Education, Nursing.

- Primary Health Care.

- Educational Measurement.

Recebido em: 08/04/2011

Aprovado em: 25/10/2011

REVISTA BRASILEIRA DE EDUCAÇ̄̃O MÉDICA 24 36 (1):2431; 2012
'Universidade Estadual Paulista "Júlio de Mesquita Filho", Botucatu, SP, Brasil.

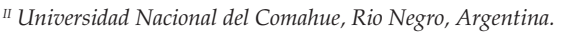

Numa faculdade com currículo tradicional e predomínio da avaliação cognitiva e somativa, uma nova disciplina, baseada na interação entre universidade, serviços e comunidade (Iusc), para estudantes de Medicina e Enfermagem numa escola de São Paulo, teve por objetivo buscar uma forma de avaliar o desenvolvimento do aluno em habilidades de comunicação e autorreflexão. A avaliação global do aluno em pequenos grupos feita por meio de relatórios escritos e portfólio do grupo não evidenciou a autorreflexão sobre o processo de aprendizagem de alguns estudantes. Foi proposto, então, um estudo piloto com 15 alunos, divididos em dois grupos, selecionados aleatoriamente, que aceitaram desenvolver um portfólio individual e reflexivo. Na análise qualitativa do material, identificou-se a presença de categorias como reflexão sobre a vida estudantil antes do curso universitário escolhido, experiências de vida que levaram à escolha profissional, correlação do aprendizado na disciplina com a prática profissional e capacidade de identificar o crescimento em habilidades de comunicação, mostrando-se eficiente no processo de autorreflexão sobre a aprendizagem.

In a multiprofessional, discipline-based curriculum with cumulative and cognitive assessment, anew discipline based on University-Community Service Interaction (IUSC), for medicine and nursing students at a São Paulo school, aimed at finding a way to evaluate students' development of communication and self-reflection skills. Overall assessment of students in small groups conducted through written reports and group portfolios failed to demonstrate self-reflection on the learning process in some students. A pilot study was therefore proposed, involving 15 students, divided into two randomly-selected groups, who agreed to develop an individual and reflective portfolio. Qualitative analysis of the material outlined categories such as reflection on student life before the chosen university course began, life experiences that led the student to the chosen career, correlation between learning the subject and professional practice and ability to identify their growth in communication skills, indicating an efficient process of self-reflection on their learning. 


\section{INTRODUÇÃO}

Nos últimos 20 anos, o cenário da educação dos profissionais da saúde viveu um momento de mudanças, no Brasil e no mundo. Foi um período de superação de um paradigma unicamente biológico em direção a um ensino que valoriza a equidade, a integralidade, a qualidade na assistência, a eficiência e a relevância do trabalho em saúde. Segundo Sá-Chaves ${ }^{1}$, nas sociedades contemporâneas, a formação dos profissionais de saúde está sendo desafiada por uma nova perspectiva, que exige a procura de novos referenciais, inscritos em novos paradigmas que interligam educação, saúde e desenvolvimento humano e sustentam a importância da formação numa perspectiva reflexiva. O paradigma de racionalidade técnica caracterizado por modelos uniformizadores e de matriz reprodutora não é mais suficiente, em suas lógicas e pressupostos, para enfrentar o desafio da formação de enfermeiros e médicos, numa perspectiva humanista e, como tal, integradora das dimensões pessoal e profissional da formação e do desenvolvimento humano.

No caso da educação médica, mudar significa formar médicos com habilidades adequadas às exigências da carreira profissional, com capacidade de oferecer atendimento de qualidade, articulando avanços tecnológicos com bom relacionamento, responsabilidade e curiosidade científica, que lhes permita recuperar a dimensão essencial do cuidado: a relação entre humanos ${ }^{2}$. Para modificar a cultura da assistência centrada no procedimento e a formação focada na doença, deve-se empreender um grande esforço a fim de melhorar a qualidade de atendimento à saúde de sujeitos e coletivos, garantindo-se maior equidade no processo de comunicação e a valorização de necessidades, expectativas e demandas dos usuários. Para responder a essas questões e ao esforço de garantir um ensino que contemple os princípios do Sistema Único de Saúde (SUS) e o compromisso com uma formação voltada ao aprimoramento dos serviços por ele prestados, propôs-se a Interação Universidade Serviços e Comunidade (Iusc) ${ }^{3}$ na Faculdade de Medicina de Botucatu.

Para melhor entendimento do contexto em que se desenvolvem as recentes mudanças ocorridas no curso de graduação em Medicina da FMB, é importante ressaltar a postura proativa da instituição frente às iniciativas de aperfeiçoamento do ensino médico promovidas em âmbito nacional nos últimos anos.

Em 2002, a FMB foi uma das 19 escolas médicas do Brasil selecionadas para o Programa de Incentivo às Mudanças Curriculares das Escolas Médicas (Promed), coordenado pelo Ministério da Saúde (MS) e pelo MEC. O principal objetivo do programa era fomentar a inovação no ensino médico, inte- grando-o ao desenvolvimento do SUS. Para tanto, as escolas médicas participantes contaram com apoio financeiro durante três anos consecutivos. A partir de 2003, a Secretaria de Gestão do Trabalho e da Educação na Saúde do Ministério da Saúde introduziu um novo incremento ao processo de mudança curricular da FMB: apresentou diretrizes de apoio a iniciativas inovadoras para articular a rede de gestão e de serviços com as instituições formadoras de profissionais da área da saúde. Visava também promover mudanças nas práticas de formação tendo em vista a integralidade da atenção à saúde da população e a educação permanente de recursos humanos para o SUS. Como resultado direto da participação nesses programas, uma atividade educacional inovadora está em desenvolvimento na FMB desde 2003: a Interação Universidade Serviços e Comunidade (Iusc). Em continuidade ao Promed, em 2006 o MS e o MEC instituíram o Pró-Saúde, projeto em que também a FMB foi selecionada para usufruir de recursos federais por mais três anos consecutivos com o objetivo de continuar a incentivar a formação de profissionais de saúde generalistas, com visão integradora do processo saúde-doença, aptos a efetivamente atuarem no SUS ${ }^{4}$.

Em 2008, a instituição apresentou projeto e foi selecionada para o PET-Saúde, uma parceria da faculdade com a Secretaria Municipal de Saúde que busca fomentar grupos de aprendizagem tutorial na Estratégia Saúde da Família (ESF), articulando o ensino na comunidade com atividades de pesquisa e extensão em Atenção Primária à Saúde. O PET-Saúde vem fortalecer uma prática acadêmica que objetiva interligar a universidade, em suas atividades de ensino, pesquisa, serviço e extensão, com demandas da sociedade.

Em 2009, a autora apresentou um projeto de avaliação formativa pelo portfólio e foi selecionada para participar do Programa de Desenvolvimento Docente para Educadores Médicos do Instituto Regional de Educação Médica Faimer Brasil, uma parceria da Universidade Federal do Ceará, Ministério da Saúde, Faimer Philadelphia e Organização Pan-Americana de Saúde. Uma parte dos trabalhos desenvolvidos é objeto deste artigo.

\section{A DISCIPLINA}

A disciplina Iusc é uma experiência construída coletivamente, a partir do reconhecimento da necessidade de vivência de alunos e professores em práticas voltadas à integralidade das ações em saúde. Baseia-se no desenvolvimento de dimensões psicossociais relevantes nas práticas educativas, voltadas à mudança da formação de profissionais da saúde voltados às necessidades do SUS. Desenvolve-se como uma atividade supradepartamental, sob a responsabilidade do Conselho 
de Curso de Graduação em Medicina e Enfermagem. Participam e participaram como professores tutores, profissionais das áreas de Biologia, Comunicação Social, Enfermagem, Fonoaudiologia, Medicina, Nutrição, Odontologia, Pedagogia, Psicologia, Serviço Social, Sociologia e Terapia Ocupacional, que contribuem com diferentes olhares e significados para o trabalho em equipe ${ }^{3}$. Desde 2008, é desenvolvida com alunos de Medicina e Enfermagem, numa proposta de integração entre os dois cursos.

A disciplina é anual, com cem horas, quatro horas semanais, com dez grupos de 12 alunos, sendo sempre três de Enfermagem e nove de Medicina, coordenados por um tutor e que permanecem na mesma área de abrangência de uma unidade da Estratégia Saúde da Família ou Policlínica durante os três primeiros anos.

Desenvolver um curso inovador num contexto cuja proposta político-pedagógica institucional é predominantemente tradicional tem sido um desafio. A Iusc trabalha com grupos de no máximo 12 a 13 alunos, na comunidade, com problematização de situações reais. Centra seu foco na família inserida no universo das relações históricas, culturais, socioeconômicas e políticas da sociedade, procurando ampliar a concepção biomédica no processo ensino-aprendizagem. Os estudantes percebem a diferença da proposta pedagógica do programa, o que, muitas vezes, gera divergências e questionamentos.

A dinâmica da disciplina exige um processo de formação contínuo dos professores, o que constitui um desafio permanente para a equipe de coordenação do programa. Apoiar e orientar os professores neste processo de compreensão da realidade, no domínio de metodologias de aprendizagem centradas no aluno, como a problematização, romper com a dicotomia teoria e prática, valorizar os esforços individuais e do grupo na busca das teorias que fundamentam os processos de mudança que estão sendo desenvolvidos são as bases desse processo de formação. ${ }^{5}$

Nos últimos anos, o grupo de professores tutores relata dificuldades e insatisfações na tarefa de avaliar os estudantes, discutindo critérios, buscando instrumentos adequados a um curso cuja proposta pedagógica é diferente daquela do ensino tradicional. Têm sido valorizados os relatos dos alunos das atividades de campo, a reflexão que fazem acerca das diferentes situações que vivenciam nas famílias visitadas. Mas, no final do ano letivo, professores e coordenadores ainda recebem devolutivas de estudantes com dificuldade de realizar uma autoavaliação do aprendizado durante o ano.

A busca de formas de avaliação que favoreçam o reconhecimento do processo de aprendizagem do estudante pelo estudante por si mesmo é hoje o centro do debate dos professores tutores.

\section{FUNDAMENTAÇÃO TEÓRICA}

O que este grupo de professores entende por avaliação? O diálogo entre aspirações do professor e a busca por referenciais teóricos, até o momento, aponta para a avaliação formativa ${ }^{6}$. Porque os professores, desde os primeiros anos da implantação da disciplina, discutiram que na Iusc uma avaliação do aprendizado baseada em prova teórica no final do curso não seria adequada, não atenderia aos objetivos da avaliação. Assim, foram elaborados e discutidos os grandes eixos da disciplina ao longo dos três anos e pactuadas diferentes formas de avaliação do aprendizado do estudante, como relatórios escritos de atividades, observação diária de cada estudante no trabalho em grupo, solicitação de relatos de atividades desenvolvidas, por escrito, com discussão em grupo periódica, leitura do material e devolutiva individual e em grupo, realizadas pelo professor com o estudante em período garantido dentro do calendário escolar.

Considerando-se este contexto, fica evidente que a opção desta disciplina é a avaliação formativa, que é contínua e realizada durante o processo de ensino e aprendizagem, com a finalidade de aprimorar as aprendizagens em curso por meio de um processo de regulação permanente. Professores e alunos estão empenhados em verificar o que se sabe, como se aprende e o que não se sabe para indicar os passos a seguir, o que favorece o desenvolvimento pelo aluno da prática de aprender a aprender ${ }^{6}$.

A avaliação torna-se formativa na medida em que se inscreve em um projeto educativo específico, o de favorecer o desenvolvimento daquele que aprende acima de qualquer outra preocupação $^{6}$

Além dos instrumentos adotados anteriormente, ao analisarem a avaliação da disciplina — realizada a cada seis meses nos três anos do curso, preenchida por estudantes, com campos com questões fechadas - e principalmente ao analisarem as questões abertas, alguns estudantes relataram dificuldades de refletir sobre o próprio aprendizado e reconhecê-lo.

Buscando aprimorar este ponto, surge a proposta de evoluir para o portfólio de grupo, que pertence ao professor tutor e membros do grupo e, mais recentemente, desde 2009, a proposta descrita neste trabalho, de introduzir um portfólio reflexivo individual do estudante.

Autores como Batista $^{7}$ consideram que o processo avaliativo de experiências formativas pressupõe práticas de avaliação como o portfólio, que representa momentos de diálogo entre docentes e discentes. Sá-Chaves ${ }^{1}$ refere-se ao portfólio reflexivo como um instrumento de diálogo entre educador e educando, que não é produzido só no término do período para fins avaliativos. Os portfólios são continuamente (re) elaborados na ação e partilhados de forma a recolherem, em tempo útil, outros modos de ver e interpretar, que facilitem ao 
aluno uma ampliação e diversificação do seu olhar, levando à tomada de decisões, ao reconhecimento da necessidade de fazer opções, de julgar, de definir critérios, além de permitir dúvidas e conflitos, para que o aluno possa emergir deles mais consciente, mais informado, mais seguro de si e mais tolerante quanto às hipóteses dos outros.

Para Anastasiou e Alves ${ }^{8}$, a expectativa é de conseguir mobilizar o estudante para a responsabilidade sobre seu processo de aprendizagem, favorecendo a análise de singularidades e peculiaridades do desenvolvimento de cada um. Com esses pressupostos, entende-se que o portfólio pode vir a constituir um instrumento capaz de dar respostas a essas expectativas. Citando Arter:

O portfólio não deve se confundir com o caderno diário, pois não se trata de um espaço onde se registram todos os trabalhos do estudante; o portfólio é uma compilação apenas dos trabalhos que o estudante entenda relevantes após um processo de análise crítica e devida fundamentação. (p. 27)

A proposta de avaliação com portfólio se fundamenta na intenção de levar adiante uma avaliação que esteja em consonância com a natureza evolutiva do processo de aprendizagem. De Sordi ${ }^{9}$ apresenta o portfólio como uma possibilidade interessante para avaliar a aprendizagem do estudante universitário de modo contínuo e processual, uma vez que reúne sistematicamente as diferentes produções dos alunos e estimula as mais diversas formas de expressões de suas qualidades. Isto faz com que se rompa com o vício de supervalorizar a prova escrita e a comunicação em situações formais previamente estipuladas pelo professor.

\section{METODOLOGIA}

Neste trabalho foi empregada a metodologia qualitativa de pesquisa, uma escolha determinada pela adequação ao tipo de questão do estudo, de cunho educacional, no campo da formação de profissionais de saúde.

A pesquisa qualitativa é aqui compreendida como um processo interativo do pesquisador com a realidade que vai estudar ${ }^{10,11}$. Ela tem suas origens nas práticas desenvolvidas inicialmente por antropólogos e, em seguida, por sociólogos em estudos sobre vida em comunidades. Só posteriormente irrompeu na investigação educacional ${ }^{12}$. Lüdke e André ${ }^{13}$ referem que os pesquisadores da área da educação vinham demonstrando interesse pelo uso da metodologia qualitativa na década de 1980.

Este estudo constitui um projeto piloto do uso do portfólio reflexivo individual do estudante de Medicina e Enfermagem no primeiro ano da disciplina Iusc
Inicialmente, foram sorteados dois grupos entre os dez nos quais se dividem os estudantes nesta disciplina. Foi apresentada a proposta do estudo a cada grupo, separadamente. Nesse dia, fez-se uma breve apresentação sobre o que é o portfólio, já que a quase totalidade dos alunos nunca tinha utilizado esse método, sobre como tem sido aplicado e de que forma poderia ser introduzido na Iusc, enfatizando o caráter reflexivo que tínhamos por objetivo e a liberdade que cada estudante teria na elaboração de seu portfólio para que o conteúdo deste realmente tivesse significado para o aprendizado do estudante. Para que não houvesse diferenças no processo de avaliação dos estudantes, o portfólio não foi considerado na finalização do conceito que cada estudante recebe na disciplina. Elaboramos uma sugestão de estrutura básica do portfólio, que foi entregue a cada um dos alunos. Quinze deles aceitaram participar voluntariamente do estudo, construindo seu portfólio individual.

Os materiais a serem analisados, segundo uma proposta de pesquisa qualitativa, foram os portfólios elaborados pelos alunos. Inicialmente, foi utilizada a técnica de análise de conteúdo de Bardin ${ }^{14}$. Segundo essa autora, a primeira etapa é a descrição, a enumeração das características do texto, resumida após tratamento. A segunda etapa é a interpretação, a significação concedida a essas características. A inferência (dedução lógica) é o procedimento intermediário que permite a passagem explícita e controlada da descrição à interpretação.

Na pré-análise, duas autoras do estudo fizeram várias leituras flutuantes das transcrições do material. Outra fase foi a leitura que possibilitou um agrupamento de ideias, que constituíram categorias temáticas. Esta categorização foi feita com base nas categorias emergentes definidas por relevância e repetição de temas. Posteriormente, essas categorias foram divididas em itens e ilustradas com exemplos dos discursos do grupo estudado.

O projeto foi aprovado pelo Comitê de Ética em Pesquisa da Faculdade de Medicina de Botucatu, Unesp (Protocolo CEP 3179-2009).

\section{Objetivo Geral}

Compreender a necessidade e adequação da avaliação formativa em disciplinas como a Iusc, tendo como instrumento o portfólio.

\section{Objetivos Específicos}

- Construção do checklist de avaliação formativa e somativa dos portfólios individuais dos estudantes, propostos para dois grupos;

- Instrumentalização teórica dos professores para o trabalho com portfólio do professor e do grupo;

- Sensibilização dos estudantes para trabalhar com o portfólio individual do estudante. 


\section{RESULTADOS E DISCUSSÃO}

A análise do material dos portfólios dos estudantes permitiu destacar como primeira categoria reflexão sobre sua vida estudantil antes do curso universitário escolhido, onde aparecem relatos de momentos importantes da vida de estudante durante o ensino médio.

Eu nunca fui a melhor aluna da sala, mas sempre fui decidida e sempre soube o que quis, tanto que tive somente uma opção de curso nos vestibulares e passei direto, sem cursinho (do que me orgulho muito). (Estudante 1)

Eu sempre fui autodidata e assim estudei até passar no vestibular. Só fiz aula de filosofia aos sábados porque filosofia é algo que liberta a mente e não há nada melhor do que você poder enxergar o mundo com seus próprios olhos, dando as costas à alienação que tenta te dominar de todas as formas. (Estudante 15)

É relevante para o professor conhecer o percurso estudantil, a preparação anterior, até para valorizar o aprendizado ao longo do curso universitário, com a possibilidade de observar o progresso dos estudantes de forma individualizada, como destaca Luckesi ${ }^{14}$, que vê a avaliação diagnóstica como possibilidade de avanço para os estudantes.

Outra categoria identificada foi reflexão sobre experiências de vida que levaram à escolha profissional na área da saúde.

Eu decidi fazer Enfermagem quando tinha 16 anos. Fiquei muito doente por um semestre e quem me deu o maior apoio, além de minha família, foram as enfermeiras. Me aconselharam e cuidaram muito, o que me ajudou na recuperação. (Estudante 4)

Que a verdade seja dita, cheguei à oitava série sem saber um décimo do que deveria saber para ingressar no ensino médio. Minha escola era basicamente formada por filhos de agricultores e, portanto, alunos sem muita perspectiva. [,,'] Por outro lado, eu sempre quis me formar em Medicina e foi por isso que lutei e hoje estou aqui. (Estudante 14)

A disciplina Iusc permite um contato próximo entre estudante e professor, porque cada grupo tem 12 ou 13 estudantes. Relatos como estes, se colocados pelo estudante no trabalho em grupo, permitem que o professor reconheça cada um e mobilize estas reflexões em momentos de dificuldade. Para alunos introvertidos, o portfólio pode constituir uma oportunidade a mais para repensarem sua história de vida e escolhas profissionais. E, para o professor, pode propiciar um conhecimento mais aprofundado das motivações de cada membro do grupo.
Autores como Luwisch, citado por Sá-Chaves ${ }^{1}$, destacam o portfólio reflexivo como uma estratégia que procura evidenciar o fluir dos processos subjacentes ao modo pessoal como cada um se apropria singularmente da informação. Ele constitui uma narrativa múltipla, de natureza biográfica, que se situa entre o aprender e o viver, enquanto construção social de suas histórias de vida.

Em relação à escolha profissional, autores como Ramos-Cerqueira e Lima ${ }^{15}$ destacam as motivações conscientes e inconscientes que levariam jovens adolescentes a uma opção profissional relacionada a dor, sofrimento e morte. Dentre as motivações conscientes - muitas vezes expressas por estudantes - , as mais apontadas são desejo de compreender, de ver, desejo de contato, prestígio social, prestígio do saber, alívio prestado aos que sofrem, atração pelo dinheiro, necessidade de ser útil, atração pela responsabilidade ou pela reparação, desejo de uma profissão liberal e necessidade de segurança.

Outra categoria importante compõe-se de considerações sobre a família elou a distância da família ao estudar numa escola no interior.

A chegada em Botucatu foi terrível, pois me vi sozinha, sendo a única estudante da Unesp Botucatu da cidade de Aguaí e sem nenhum conhecido nesse lugar, que até então era estranho. (Estudante 1)

Aqui estou, mudança radical de vida para quem nunca morou longe dos pais, a menininha pantaneira voou em busca de seus sonhos. Botucatu, nem sabia que esta cidade existia. Mais de $800 \mathrm{~km}$ longe da outra parte de mim... minha família e meus amigos. (Estudante 15)

O distanciamento de pessoas que você ama é inevitável, antes você os via todos os dias e agora tem que se contentar com uma vez por semana. Tudo isso porque você cresceu e agora está amadurecendo de forma forçada, tem de se tornar responsável e construir o seu futuro. (Estudante 8)

Ramos-Cerqueira e Lima ${ }^{15}$ destacam que, em alguns casos, à adaptação à universidade soma-se a experiência de sair de casa pela primeira vez e suas consequências: não há garantia de afeto e de cuidados que assegurem a sobrevivência no cotidiano, acentuando ainda mais a insegurança adolescente. Tudo está por sua conta: organizar o dia a dia, descobrir um jeito novo de estudar e estabelecer novos vínculos afetivos. Nessa nova vida, o jovem enfrentará o contato com pessoas diferentes, a ameaça do trote, as festas, a bebida, as drogas e as primeiras decepções.

Relatos como os descritos acima permitem ao professor estar atento, porque, segundo estudos nacionais e internacionais, estudantes de Medicina e Enfermagem podem desenvol- 
ver ansiedade e depressão numa proporção maior que alunos de outras profissões. Zonta et al. ${ }^{16}$ citam pesquisas de Miller e Surtees, que, ao estudarem a evolução de sintomas de ansiedade e depressão entre estudantes de Medicina do primeiro ano em seus primeiros seis meses na universidade, concluíram que um pequeno subgrupo continuamente sintomático continha estudantes mais lentos para fazer amizades, com suporte inapropriado dos familiares, com tendência de brigar, com namorados(as) firmes e/ou personalidades "vulneráveis".

Por outro lado, o subgrupo que esteve bem por todo o período tinha experimentado uma infância com muitos cuidados, raramente tinha namorados(as), mostrou pequena tendência para brigas e tinha personalidade "adaptativa".

O professor que atua como conselheiro também em questões relativas ao período de adaptação do estudante à nova vida universitária pode constituir uma rede de apoio social importante.

A análise do material escrito dos alunos evidenciou a valorização da produção do próprio estudante como algo que ele destaca na disciplina.

É mais interessante o aluno demonstrar o que realmente aprendeu e julgou importante para a sua vida do que fazer relatórios sobre o que ele às vezes viu e não absorveu e receber uma nota que muitas vezes não reflete seu real conhecimento. O portfólio ajuda o aluno a fazer uma autoavaliação e não apenas receber o parecer do professor. (Estudante 12)

Afinal, é a primeira vez que tenho a liberdade de expressar de forma simples e direta minhas opiniões, sem generalizações, sem acordo com o auditório universal, nada simplesmente além de um diário acadêmico. (Estudante 5)

O importante não é o portfólio em si, mas o que o estudante aprendeu ao criá-lo ou, dito de outro modo, o portfólio é um meio para atingir um fim e não um fim em si mesmo. Conforme Sá-Chaves ${ }^{1}$, constata-se que o portfólio é, simultaneamente, uma estratégia que facilita a aprendizagem e permite a avaliação da mesma.

As autoras foram surpreendidas no estudo dos portfólios, considerando que foram desenvolvidos no segundo semestre do primeiro ano, durante quatro meses apenas, com relatos sobre aprendizados na disciplina Iusc e sobre outras disciplinas do primeiro ano.

Muito bem, fiz tudo o que mandaram e passei em Medicina. No entanto, nem tudo são flores: como em todo começo de curso, há aquelas matérias que são muito chatas. E nesse sufoco de estudar bioestatística, biochatice, bio-não-sei-das-quantas, eis que surge uma janela para eu pegar um ar: a
Iusc. Um curso com espaço para discussão e interação com a comunidade é um "prato cheio" para quem gosta de falar como eu. Ele me deu voz e ouvidos diante dos meus colegas e diante da comunidade. (Estudante 5)

Somente depois daquela reunião, da qual eu não esperava grande coisa, foi que eu pude finalmente compreender e vivenciar a verdadeira proposta da Iusc. (Estudante 6)

Também foram inesperados os relatos relacionados a $u m a$ correlação do aprendizado na disciplina com a prática profissional.

Esse conhecimento é relevante no sentido de tornar possível uma antecipação das doenças que terão de ser tratadas no futuro, quando iniciar a prática médica, pois será obtido um conhecimento geral da comunidade, especialmente da minha área de abrangência, Jardim Aeroporto. (Estudante 2)

De lado das críticas, considero positivas e muito relevantes para minha formação médica, principalmente na relação médico-paciente, as atividades desenvolvidas e as visitas domiciliares. (Estudante 5)

Particularmente, gostei muito da Iusc. Com ela aprendi a trabalhar mais em equipe, aceitar opiniões diversas, ouvir mais as pessoas e tentar entendê-las. Acho também que a relação com o indivíduo é muito importante numa carreira em que lidar com o próximo é uma constante. (Estudante 14)

Quanto aos aprendizados citados, seriam necessários estudos longitudinais de portfólios dos estudantes para que se pudesse determinar a influência da disciplina na formação de um profissional de saúde adequado à futura prática profissional. Autores como Prados ${ }^{17}$ valorizam o portfólio como instrumento para competências relacionadas ao desempenho profissional e para uma formação contínua do profissional que atua em Atenção Primária ${ }^{18,19}$.

Houve muitas citações dos estudantes em relação ao aprendizado sobre trabalho em grupo. Escolhemos algumas falas mais significativas e que se repetem neste grupo de estudantes analisado.

O trabalho em grupo, as visitas domiciliares, as discussões posteriores foram importantes devido à troca de informações, pois cada um de nós adquire conhecimento distinto em relação a cada situação vivenciada. (Estudante 8)

Encontramos naquele dia um espaço saudável de discussão de ideias como nunca esperávamos e descobrimos qualidades de nossos colegas que se encontravam obscurecidas por outros aspectos mais marcantes de suas personalidades. (Estudante 6) 
A Iusc também é importante no que se refere ao trabalho em grupo. Eu considero essa parte muito difícil da vida acadêmica, pois num grupo de 11 pessoas como o nosso a diversidade de ideias é muito grande. (Estudante 14)

A capacidade de trabalhar em grupo e de forma multiprofissional e interdisciplinar destacada nas diretrizes curriculares ${ }^{20,21}$ de cursos como Medicina e Enfermagem é uma competência que precisa ser exercitada ao longo de todo o processo de formação. Os grupos da Iusc são formados sempre com estudantes de Medicina e Enfermagem. Os professores, de diferentes profissões, buscam apoiar o grupo no reconhecimento de aprendizados relevantes para estudantes das profissões da saúde, como saber ouvir, discutir e permitir a participação de todos num trabalho coletivo que valorize as potencialidades de cada um.

Peduzzi ${ }^{22}$ destaca que o trabalho em equipe na saúde da família requer a compreensão das várias disciplinas para lidar com a complexidade que é a Atenção Primária, que toma a saúde no seu contexto pessoal, familiar e social, bem como com a promoção da saúde e a prevenção e reabilitação, trazendo a intersetorialidade como parceira na resolutividade dos problemas de saúde.

Como última categoria, destacou-se o desenvolvimento pelo estudante de habilidades de comunicação.

Fiquei surpreso ao perceber que conseguia conversar tranquilamente com a mãe da criança mesmo sem nunca tê-la visto. $\mathrm{O}$ assunto transcorria normalmente como se eu estivesse conversando com um conhecido. (Estudante 2)

Assim, são exercitadas habilidades de escuta, compreensão acerca da realidade de cada família em particular. Isso se torna extremamente importante não apenas no sentido de estabelecer um primeiro contato, mas também de conhecer a própria comunidade, seus problemas e dificuldades enfrentadas

Ferreira et al. ${ }^{23}$, confirmando as falas citadas acima, relatam, em estudo com estudantes de primeiro e segundo ano de Medicina na atenção básica, que os alunos reconhecem que o trabalho na comunidade favorece o desenvolvimento de relações interpessoais e de comunicação essenciais à sua formação.

\section{CONSIDERAÇÕES FINAIS}

O estudo está numa fase ainda preliminar. Professores e estudantes se acham diante do desafio de aprofundar seus conhecimentos no campo da avaliação formativa e diagnóstica, que busca eventos-sentinela que sinalizem para o grupo formulador da disciplina os caminhos a serem percorridos, a busca do desenvolvimento de competências, habilidades e atitudes do profissional de saúde para o século XXI.

No dizer de Villas Boas ${ }^{24}$, uma estudiosa de portfólio, “a antiga prática de transmissão de conhecimentos, de trabalho isolado e solitário por parte dos alunos e de avaliação unilateral, seletiva e excludente está cedendo lugar ao processo de trabalho em que predominam a construção, a reflexão, a criatividade, a parceria, a autoavaliação e a autonomia".

Investigar novas formas de avaliação numa disciplina inovadora é assumir o pressuposto de que em educação mudar não é suficiente. É preciso acompanhar o processo de desenvolvimento das novas disciplinas e avaliar de forma coerente o estudante que participa destas experiências educacionais.

\section{REFERÊNCIAS}

1. Sá-Chaves I, org. Os "Portfolios" Reflexivos (também) trazem gente dentro. Porto: Porto Editora; 2005.

2. Cyrino EG, Rizzato ABP. Contribuição à mudança curricular na graduação da Faculdade de Medicina de Botucatu. Rev Bras Matern Infant. 2004;4(1):59-69.

3. Cyrino EG, Prearo AY, Denzan EB, Romanholi EMZ, Quarentei MS, org. A universidade na comunidade: educação médica em transformação. Botucatu: UNESP; 2005.

4. Universidade Estadual Paulista "Júlio de Mesquita Filho". Projeto Político-pedagógico [homepage]. Botucatu: UNESP; [acesso em 31 abr. 2010]. Projeto Pedagógico do Curso de Graduação em Medicina da Faculdade de Medicina de Botucatu. Disponível em: http:/ / www.fmb.unesp. br/projetopedagogico/projeto.php

5. Cyrino EG, Martins STF, Prearo AY, Manoel CM, Oikawa LT, Vecchia MD, et al. Em busca da recomposição da arte do cuidado e do fazer / aprender: a interação universidade, serviço, comunidade na FMB/UNESP. In: Pinheiro R, Ceccim RB, Mattos RA, org. Ensino-trabalho-cidadania. Rio de Janeiro: Abrasco; 2006. p.71-84.

6. Hadji C. Avaliação desmistificada. Porto alegre: Artmed; 2001.

7. Batista N, Batista SH, Goldenerg P, Seiffert O, Sonzogno MC. O enfoque problematizador na formação de profissionais da saúde. Rev Saúde Publica. 2005;39(2):231-7

8. Anastasiou LGC, Alves LP. Processos de Ensinagem na Universidade: pressupostos para as estratégias de trabalho em aula. 7aㅡ ed. Joinville, SC: UNIVILLE; 2007.

9. De Sordi MRL, Malawasi MMS. As duas faces da Avaliacão: da realidade à utopia. Rev Educ Puc-Campinas. 2004;17:105-15.

10. Minayo MCS. O desafio do conhecimento: pesquisa qualitativa em saúde. 2ª̣ed. São Paulo: Hucitec; 1993. 
11. Shraiber LB. Medicina tecnológica e prática profissional contemporânea: novos desafios, outros dilemas. São Paulo; 1997. Livre-docência [Tese] - Faculdade de Medicina, Universidade de São Paulo.

12. Triviños ANS. Introdução à pesquisa em Ciências Sociais: a pesquisa qualitativa em educação.São Paulo: Atlas; 1987.

13. Ludke M, André MEDA. Pesquisa em educação: abordagens qualitativas. São Paulo: EPU;1986.

14. Bardin L. Análise de conteúdo. Lisboa: Edições 70; 1977.

15. Ramos-Cerqueira ATA, Lima MC. La Formación de la identidad médica: implicaciones para la enseñanza de graduación en Medicina. Interface Comunic Saúde Educ. 2002;6(11):107-16.

16. Zonta R, Robles ACC, Grosseman S. Estratégias de enfrentamento do estresse desenvolvidas por estudantes de Medicina da Universidade Federal de Santa Catarina. Rev Bras Educ Med. 2006;30(3):147-53.

17. Prados JA. Preguntas sobre la evaluación de la competência y alguna respuesta: Portfólio. Atencion Primaria. 2005;36:3-4.

18. Mathers NJ, Challis MC, Howe AC, Field NJ. Portfolio in continuing medical education-effective and efficient? Med Educ. 1999;33:521-30.

19. Challis M. AMEE 11 Medical Education Guide. Portfolio-based learning and assessment in medical education. Med Teacher. 1999;21(4):370-86.

20. Brasil. Ministério da Educação. Conselho Nacional de Educação. Câmara de Educação Superior. Resolução CNE/ CES n. ${ }^{\circ}$ 4, de 7 de novembro de 2001. Institui diretrizes curriculares nacionais do curso de graduação em medicina. Diário Oficial da União. Brasília, 9 nov. 2001; Seção 1, p.38.

21. Brasil. Ministério da Educação.Conselho Nacional de Educação. Câmara de Educação Superior. Resolução CNE/
CES n`3, de 7 de novembro de 2001. Institui diretrizes curriculares nacionais do curso graduação em enfermagem. Brasília, 2001.

22. Peduzzi M. Equipe multiprofissional de saúde: a interface entre trabalho e interação. Campinas; 1998. Doutorado [Tese] - Faculdade de Ciências Médicas, Universidade Estadual de Campinas.

23. Ferreira RC, Silva RF, Aguer CB. Formação do Profissional Médico: a Aprendizagem na Atenção Básica de Saúde. Rev Bras Educ Med. 2007;31(1):52-9.

24. Villas Boas BMF. O portfólio no curso de pedagogia: ampliando o diálogo entre professor e aluno. Educ Soc. 2005;26(90):291-306.

\section{CONTRIBUIÇÃO DOS AUTORES}

Todas as autoras participaram na elaboração do desenho do estudo e do seu desenvolvimento. Elena Barragán também fez a revisão do resumo em língua inglesa.

\section{CONFLITO DE INTERESSES}

Declarou não haver.

\section{ENDEREÇO PARA CORRESPONDÊNCIA}

Alice Yamashita Prearo

Departamento de Pediatria e Núcleo de Apoio Pedagógico da FMB

Faculdade de Medicina de Botucatu - UNESP

Distrito de Rubião Júnior, $\mathrm{s} / \mathrm{n}^{\mathrm{o}}$

Botucatu - São Paulo

CEP 18618-970 — SP

E-mail: btalice@fmb.unesp.br 